\title{
PENENTUAN TEBAL PERISAI RADIASI PERANGKAT RADIOTERAPI EKSTERNAL C0-60 UNTUK POSISI PENYINARAN
}

\author{
Kristiyanti, Budi Santoso, Leli Yuniarsari, Wiranto B.S. \\ Pusat Rekayasa Perangkat Nuklit - BATAN \\ Kawasan Puspiptek Serpong Gedung 71, Tangerang-15310 \\ E-mail : kristiyantiwst@yahoo.com
}

\begin{abstract}
ABSTRAK
PENENTUAN TEBAL PERISAI RADIASI PERANGKAT RADIOTERAPI EKSTERNAL C0-60 UNTUK POSISI PENYINARAN. Telah dilakukan perhitungan tebal perisai radiasi pada kepala gantri perangkat radioterapi eksternal Co-60 untuk posisi penyinaran. Posisi penyinaran adalah ketika sumber $\mathrm{Co}$ 60 dikeluarkan untuk melakukan terapi ke pasien. Perisai radiasi dimaksudkan untuk melindungi bagian tubuh pasien yang tidak diterapi sehingga bagian tersebut terlindungi dari paparan tadiasi sesuai dengan ketentuan keselamatan radiasi. Perhitungan ini bertujuan untuk menentukan tebal perisai radiasi sertajenis bahan yang digunakan. Perhitungan berdasarkan prinsip pelemahan berkas radiasi garnma $(\gamma)$ dan ketentuan keselamatan radiasi yang diatur BAPBTEN. Dari hasil perhitungan didapatkan bahwa pada saat penyinaran dilakukan, perisai radiasi untuk bagian atas dan samping menggunakan bahan timbal (Lead/Plumbum-Pb) dengan tebal $21 \mathrm{~cm}$. sedangkan untuk bagian bawah menggunakan bahan tungsten (Wolfram-W) dengan tebal $13 \mathrm{~cm}$, dan kolimator dari $\mathrm{Pb}$ dengan tebal $21 \mathrm{~cm}$, Dengan perhitungan perisai radiasi ini, paparan yang diterima bagian tubuh pasien yang tidak diterapi adalah kurang dari setengah dari nilai batas dosis $(0,5$ inSv). Dengan demikian dapat disimpulkan bahwa hasil perhitungan perisai radiasi pada posisi penyinaran ini memenuhi ketcrituan keselamatan yang dipersyaratkan.
\end{abstract}

Kuta kunci : Radioterapi eksternal, perisai radiasi, tebal, timbal, Tungsten

\section{ABSTRACT}

THE DETERMINATION OF SHIELDING THICKNESS CO-60 EXTERNAL RADIOTHERAPY GANTRY HEAD FOR BEAM-ON POSITION. The colculation of Ca-60 external radiotherapy gantry head shielding for beam-on position has been done. Beam-on pasition is the position when Co-60 source is exposed in order to therapy a patient. The shielding is intended to protect parts of patient body which are not therapied so that they are protected from radiation exposure in conjuntion with radiation safety regulations. The design is intended ta determine thickness and material topes of radiation shieldings which will be utilized. The design calculation is based on gamma (t) radiation attemiation principles and has to comply with radiation safety requitements regulated by BAPETEN. From the result of calculation. Co-60 external radioteherapy gantry head shielding for beam-on position consist of Lead (Plumihum-Pb) with $21 \mathrm{~cm}$ thickness for upper and sides parts. Turgsten (Wolfram-W) with $13 \mathrm{~cm}$ thiclaness for bottom parts, and Lead with $21 \mathrm{~cm}$ thickness for collimator. Result of radiation shielding design shows that parts of patient body which are not therapied will receive less than half of dose limit value $(0,5 \mathrm{mSv})$ radiation exposate so that it meets the requiced safety regulations.

Keywords: external radiotherapy. radiation shielding, thickness. lead tungsten 


\section{ENDAHULUAN}

Perangkat radioterapi eksternal enggunakan $\mathrm{CO}-60$ berfungsi untuk terapi -sien kanker dengan cara memberikan radiasi mua $(\gamma)$ dari radioisotop Co-60. Di Sonesia hanya terdapat 20 rumah sakit yang emiliki fasilitas radioterapi. Sedikitnya Litas radioterapi di Indonesia antara lain ebabkan oleh harga perangkat radioterapi ng mahal. Karena itu diperlukan agembangan kemampuan lokal untuk cnghasilkan perangkat radioterapi. Dengan mikian pelayanan terapi kanker untuk asyarakat Indonesia dapat ditingkatkan. rehitungan dilakukan dengan mengambil cuan perangkat radioterapi menggunakan $\mathrm{Co}$ yang ada di rumah sakit Hasan Sadikin RSHS) Bandung 11 . Perangkat Radioterapi Sajikan seperti pada Gambar.1.

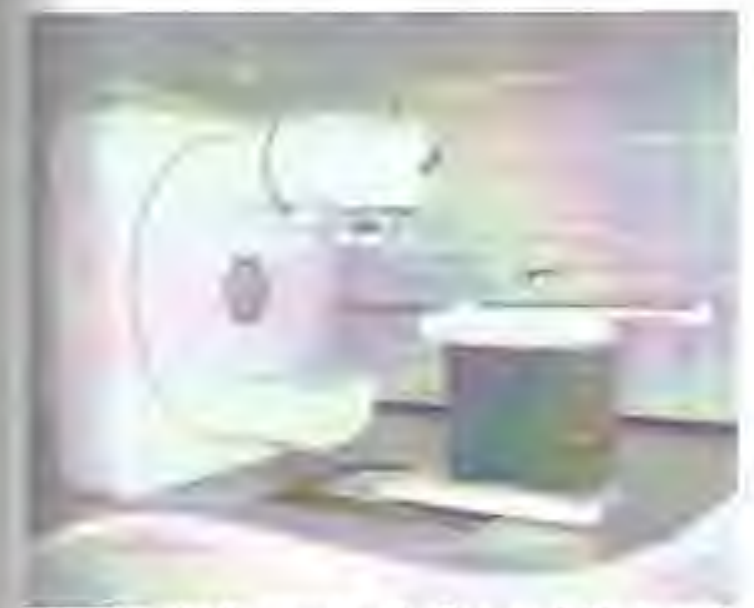

Gambar 1. Perangkat Radioterapi Ekstemal

Perhitungan rancangan berdasarkan pelemahan berkas radiasi $\gamma$ dari radioisotop Co-60. Bagian dari perangkat tersebut antara Lain terdiri dari kepala sumber, yaitu tempat radioisotop berada. Radioisotop pada saat penyimpanan atau pada saat tidak melakukan penyinaran akan berada pada posisi beam off sedangkan pada saat melakukan penyinaran betada pada posisi beam on, yaitu pada saat sumber berada pada posisi di atas kolimator.

Perangkat Radioterapi pada bagian kepala sumber seperti pada Gambar 2.

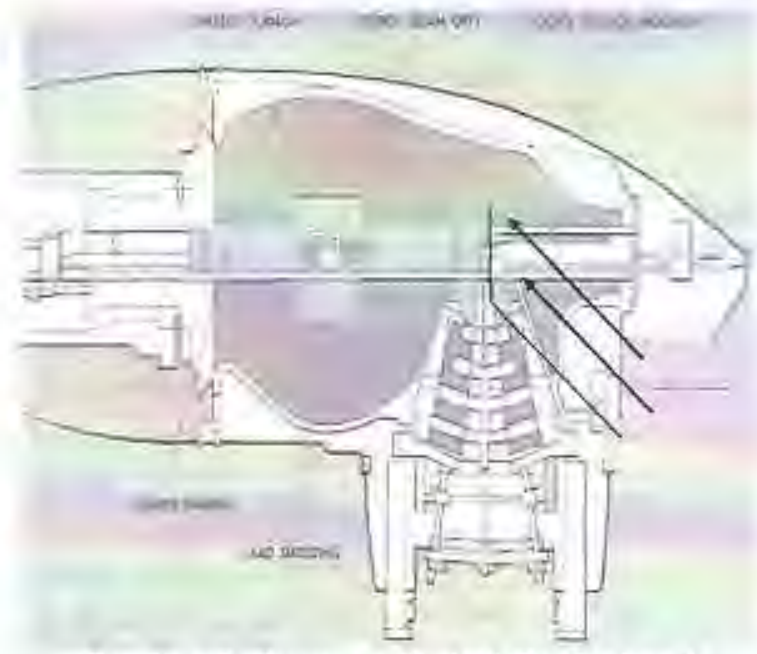

Gambar 2. Susunan Perisai Radiasi pada Kepala Sumber

Pada saat penyimpanan, sumber radioisotop Co-60 sudah terlindungi oleh perisai radiasi yang terdiri dari bahan timbal $(\mathrm{Pb})$, tungsten $(\mathrm{W})$ dan juga depleted uranium (DU). Dalam makalah ini akan dibahas perhitungan ketebalan perisai radiasi pada saat penyinaran dengan posisi sumber isotop terarah pada pasien, sehingga bagian tubuh pasien yang tidak perlu diterapi terlindungi dengan perisai radiasi dan terhindar dari paparan radiasi. Bahan perisai radiasi yang akan digunakan terdiri dari $\mathrm{W}$ dan $\mathrm{Pb}$, Bahan dari $W$ digunakan karena akan memberikan bentuk yang lebih kecil dan lebih ringan sedangkan bahan $\mathrm{Pb}$ digunakan untuk kolimator yang berfungsi untuk menyearahkan penyinaran.

Dengan menggunakan perisai radiasi maka diharapkan perangkat Radioterapí bisa memenuhi ketentuan keselamatan yang telah ditetapkan.

\section{METODE}

Optimasi proteksi dan keselamatan radiasi harus diupayakan agar paparan radiasi terhadap pasien minimum sesuai dengan yang diperlukan untuk mencapai tujuan radioterapi. Paparan radiasi terhadap jaringan normal selama radioterapi dipertahankan serendah mungkin yang dapat dicapai sesuai dengan pemberian dosis yang diperlukan pada volume target.

Sesuai dengan Peraturan Kepala Badan Pengawas Tenaga Nuklir (BAPETEN) Nomor 3 Tahun 2013 disebutkan bahwa Nilai Batas Dosis (NBD) untuk anggota masyarakat tidak boleh melampaui dosis efektif sebesar $1 \mathrm{mSv}$ 
dalam satu tahun. Bagian tubuh pasien yang yang terlindungi sesuai dengan penerapan optimasi proteksi dan keselamatan radiasi hanya boleh menerima paparan radiasi $1 / 2$ (satu per dua) dari NBD ${ }^{|2|}$

NBD adalah dosis terbesar yang diizinkan oleh BAPETEN yang dapat diterima oleh pekerja radiasi atau anggota masyarakat dalam jangka waktu tertentu tanpa memberikan efek genetik dan somatik yang berarti akibat pemanfaatan tenaga nuklir.

Perangkat Radioterapi akan memberikan dosis serap dengan satuan Gray pada setiap pasien. Untuk menghitung dosis efektif yang diterima pasien digunakan persamaan ekuivalensi dosis: dengan:

$$
\mathrm{SV}=\operatorname{Rad} \times \mathrm{W}_{\mathrm{R}} \times \mathrm{W}_{\mathrm{T}}
$$

$$
\begin{aligned}
& \text { Sv = satuan dosis efektif } \\
& \text { Rad = satuan dosis serap } \\
& W_{R}=\text { faktor bobot radiasi } \\
& W_{T}=\text { faktor bobot jaringan } \\
& I \mathrm{~Gy}=100 \mathrm{Rad}
\end{aligned}
$$

Faktor bobot radiasi $\left(\mathrm{W}_{R}\right)$ ditentukan berdasarkan jenis dan energi radiasi, sedangkan faktor bobot jaringan $\left(\mathrm{W}_{T}\right)$ digunakan untuk dosis serap didalam setiap organ.

Perhitungan perisai radiasi untuk radioisotop Co-60 pemancar sinar $(\gamma)$ berdasarkan prinsip pelemahan berkas radiasi $\gamma$ digunakan Persamaan ${ }^{[3]}$,

$$
I=I o, e^{-\mu t}
$$

dengan :

Io dinyatakan sebagai paparan radiasi sebelum melewati perisai radiasi

I dinyatakan sebagai paparan radiasi sesudah melewati perisai radiasi besarnya sesuai dengan NBD yang telah ditentukan.

$\mu$ koefisien atenuasi linier bahan yang nillainya bisa didapatkan dari koefisien atenuasi massa $(\mu / \rho)$.

t tebal dari perisai.

Dari hasil perhitungan tebal perisai masih harus ditambah dengan faktor bentuk yaitu Build Up factor (B), digunakan Persamaan (3) dit:

$\frac{I}{I o}=B \cdot e^{-\mu t}$

Faktor bentuk B adalah faktor pertumbuhan yang mempunyai nilai $>1$. Faktor $B$ bergantung pada energi radiasi, nomor atom bahan dan juga pada tebal perisai.
Harga B bisa dilihal pada Gambar 3. titu kurva faktor pertumbuhan dosis untuk berbagai energi radiasi dalam bahan timbal (lead $)^{|s|}$. Dengan memasukkan harga $\mu$ dan energi isotop yang digunakan maka bisa diketahui harga B.

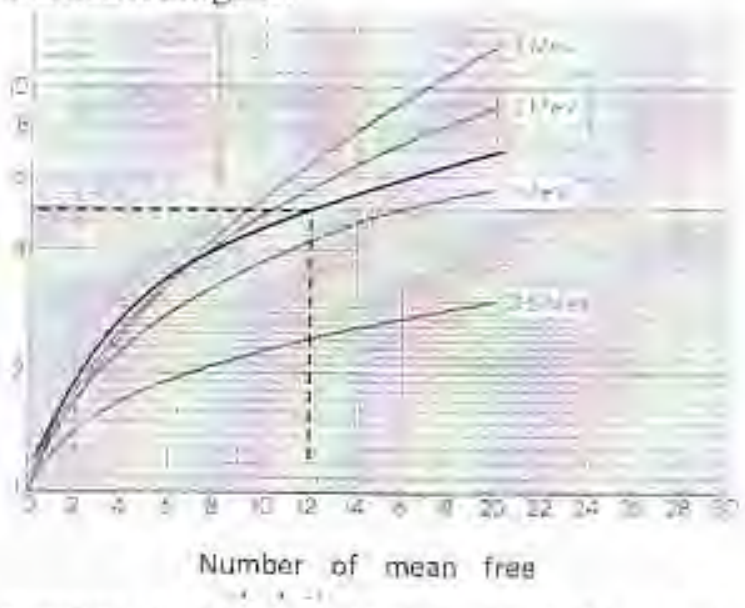

Gambat 3. Kurva faktor pertumbuhan dosis untuk berbagai energi radiasi dalam bahan timbal

Dari hasil perhitungan yang telah dilakukan, diketahui bahwa harga i yang dibitung dengan Persamaan (3) akan terlalu tipis ${ }^{[4]}$, karena itu perlu ditambah tebalnya.

Tebal perlu ditambah lapisan setebal n Half Value Layer (HVL) menjadi $t^{\prime}$ sesuai dengan Persamaan:

$$
t^{1}=t+n \cdot H V L
$$

HVL adalah tebal lapisan perisai yang diperlukan untuk menjadikan besaran semula menjadi setengahnya.

Nilai HVL dapat diketahui dari hubungan

$$
H V L=0,693 / \mu
$$

Perhitungan diulang dengan cara menambah harga $t$ dan memasukkan harga $B$ pada Pers. (3), sampai diperolah harga I sesuaí dengan dosis yang diinginkan.

Untuk menghitung daya serap radiasi (I/I $\left.I_{0}\right)$ digunakan substitusi dari Persamaan (2) didapatkan Persamaan (6)

Daya serap $=I_{0}-1=\left(1-e^{-{ }^{21}}\right)$

Jika diinginkan bahan perisai yang berbeda, maka dengan menggunakan prinsip ekuivalensi daya serap yang sama, tebal bahan bisa dicari dengan cara substitusi dari Pers. (6) sehingga dihasilkan Persamaan (7).

$\mu_{1} t_{j}=\mu_{2} t_{2}$ dengàn :

$i_{i}=$ lebal bahan $(i=1,2, \ldots \ldots)$ 
$\mu_{4}=$ koefisien atenuasi linier bahan ( $i=1$, $2, \ldots .$.

\section{Perhitungan}

Susunan perisai pada posisi penyinaran terdiri dari :

\section{- Perisai bagian atas dan samping \\ - Perisai bagian bawah.}

Untuk menghitung tebal $\mathrm{Pb}$ dan $\mathrm{W}$ dibutuhkan data $\mu$ yang bisa diperoleh dari nilai koefisien linier massa pada energi sesuai sumber radiasi yang digunakan yaitu $\mathrm{Co}-60$ yang mempunyai energi $1,17 \mathrm{MeV}$ dan 1,33 $\mathrm{MeV}$. Dalam perhitungan ini diambil energi sumber radiasi rata-rata $1,25 \mathrm{MeV}^{[f i}$. Harga koefisien linier $\mu$ pada energi 1,25 MeV disajkan seperti pada Tabel 1.

Tabel 1. Harga koefisien linier bahan $(\mu)$ pada energi $1,25 \mathrm{MeV}^{[7]}$

\begin{tabular}{llll}
\hline Unsur & $\begin{array}{l}\mu / \rho \\
\left(\mathrm{cm}^{2} / \mathrm{gr}\right)\end{array}$ & $\begin{array}{l}\rho \\
\left(\mathrm{gr} / \mathrm{cm}^{3}\right)\end{array}$ & $\begin{array}{l}\mu \\
\left(\mathrm{cm}^{-1}\right)\end{array}$ \\
\hline $\mathrm{Pb}$ & 0,05945 & 11,34 & 0,674 \\
$\mathrm{~W}$ & 0,0563 & 19,3 & 1,0866 \\
\hline
\end{tabular}

\section{A. PERISAI BAGLAN ATAS DAN SAMPING}

Penyinaran direncanakan selama terapi sebanyak 10 kali dan dilakukan pada tahun yang sama. Bagian tubuh lain yang tidak terkena langsung penyinatan dengan asumsi batas dosis $1 / 2$ kali NBD (1 mSv) sesuai ketentuan, maka dosis yang diperbolehkan sebesar $1 / 2$ mSv per tahun.

Jika dosis serap yang diberikan ke pasien 2 $\mathrm{Gy}^{\left[{ }^{[B]}\right.}$ untuk sekali terapi, maka dengan menggunakan Pers. (1) dosis efektif untuk kulit yang diterima pasien :

Faktot bobot radiasi $\mathrm{Wr}=1$ dan

faktor bobot jaringan kulit Wt $=0.01$

dosis serap $=2 \mathrm{~Gy}-200 \mathrm{rad}$

Dosis efektif $=200 \times 1 \times 0,01$

$$
\begin{aligned}
& =2.5 \mathrm{v} \\
& =2.000 \mathrm{mSv}
\end{aligned}
$$

Jika dalam terapi dilakukan $30 \mathrm{kali}$ penyinaran maka dosis efektip yang diterima pasien $=2.000 \mathrm{mSv} \times 30=60.000 \mathrm{mSv}$

Harga koefisien linier bahan $\mathrm{Pb}$ untuk energi dari Co-60 sesuai Tabel $I, \mu=0,674$ $\mathrm{cm}^{-1}$, Perhitungan tebal perisai dari $\mathrm{Pb}$ dihitung dengan menggunakan Pers. (2).

$$
0,5=60.000 \cdot e^{-(0,674) t}
$$

dari hasil perhitungan didapat tebal perisai radiasi $\mathrm{Pb}(\mathrm{t})=17.35 \mathrm{~cm}$

Ketebalan tersebut jika dimasukkan dalam Pers. (3), didapatkan harga $1=2,30$ $\mathrm{mSv}$ tetapi harga tersebut belum memenuhi nilai batas dosis, sehingga tebal masih harus ditambah 0,5 HVL.

Nilai HVL dihitung dari Pers. (5).

Didapatkan harga HVL $=1,028$

Tebal menjadi $\mathrm{t}^{\mathrm{t}}=17,35+0,5 \mathrm{HVL}=17,864$ $\mathrm{cm}$

$$
\mu \mathrm{t}^{\prime}=12,04
$$

dari Gambar 3 didapat harga $B=4,6$

Dengan menggunakan Pers. (3) didapat harga I yaitu intensitas atau dosis setelah melalui perisai radiasi $=1,63 \mathrm{mSv}$.

Perhitungan diulang dengan menambah tebal seperti cara di atas, Begitu seterusnya sampai didapatkan harga $1<0,5 \mathrm{mSv}$, sehingga didapatkan tebal $\mathrm{Pb}=19,92 \mathrm{~cm}$.

\section{B. PERISAI BAGIAN BAWAH}

Untuk mengurangi berat kepala sumber maka bagian bawah Beam on dipasang perisaj dari bahan Tungsten (W).

Jika dikehendaki bahan $\mathrm{W}$ mempunyai daya serap yang sama bahan $\mathrm{Pb}$, maka tebal bahan perisai $W$ bisa dicari dengan mengounakan Pers. (7).

$(0,674) \cdot(19,92)=(1,0866) \cdot\left(\mathrm{L}_{w}\right)$

$$
\left(\mathrm{t}_{\mathrm{n}}\right)=12,356 \mathrm{~cm}
$$

\section{HASIL DAN PEMBAHASAN}

Hasil perhitungan tebal perisai radiasi dengan intensitas setelah melewali $\mathrm{Pb}$ seperti disajikan dalam Tabel 2.

Tabel 2. Hasil perhitungan tebal perisài radiasi dengan intensitas setelab melewati $\mathrm{Pb}$

\begin{tabular}{llll}
\hline $\begin{array}{l}\text { Tebal } \\
(\mathrm{cm})\end{array}$ & $\mu \mathrm{( \textrm {gr } / \mathrm { cm } ^ { 2 } )}$ & $\mathrm{B}$ & $\mathrm{I}(\mathrm{mSv})$ \\
\hline 17,35 & 11,69 & 4,6 & 2,30 \\
17,86 & 12,04 & 4,6 & 1,63 \\
18,38 & 12,38 & 4,7 & 1,18 \\
18,89 & 12,73 & 4,7 & 0,85 \\
19,40 & 13,08 & 4,8 & 0.60 \\
19,92 & 13,43 & 4,9 & 0,43 \\
\hline
\end{tabular}

Dari Tabel 2 didapatkan untuk tebal 19.92 $\mathrm{cm}$, maka harga I sudah $<0.5 \mathrm{mSv}$, sehingga ketebalan perisai sudah mencukupi.

Dari perhitungan menggunakan RadPro Calculation didapatkan tebal perisai radiasi $\mathrm{Pb}$ $=20,3 \mathrm{~cm}$, sedangkan tebal $\mathrm{W}=12.6 \mathrm{~cm}^{[9]}$. 
Dalam perancangan ini digunakan tebal $\mathrm{Pb}=21 \mathrm{~cm}$ dan tebal menggunakan $\mathrm{W}=13$ $\mathrm{cm}$.

Jadi pada saat penyinaran dibutuhkan perisai radiasi untuk bagian atas, samping dan bagian bawah jika menggunakan bahan dari $\mathrm{Pb}$ dibutuhkan tebal $21 \mathrm{~cm}$. Perisai radiasi bagian bawah menggunakan bahan dari $W$ untuk perisai yang tetap, tebal $13 \mathrm{~cm}$.

Untuk penyearah paparan atau kolimator digunakan bahan dari $\mathrm{Pb}$ yang terdiri dari segmen sirip, yang tiap segmen sirip mempunyai ketebalan $3 \mathrm{~cm}$, sehingga dibutuhkan 7 segmen sirip, total tebal kolimator menjadi $21 \mathrm{~cm}$. Bentuk segmen sirip ini berfungsi untuk mengatur besar kecilnya lubang penyinaran.

Besar kecilnya lubang penyinaran tergantung dari kebutuhas pasien. jika dibutuhkan lubang penyinaran sempit, maka kolimator akan merapat sehingga bagian tubuh lain hanya terlindungi dari perisai W yarkg masih aman dari paparan yang tidak dibutulikan

Perisal bagian atas dan samping bersifat stabil dibutuhkan tebal $\mathrm{Pb} 21 \mathrm{~cm}$.

Hasil rancangan susunan perisai radiasi pada kepala sumber disajikan pađa Gambar 4.

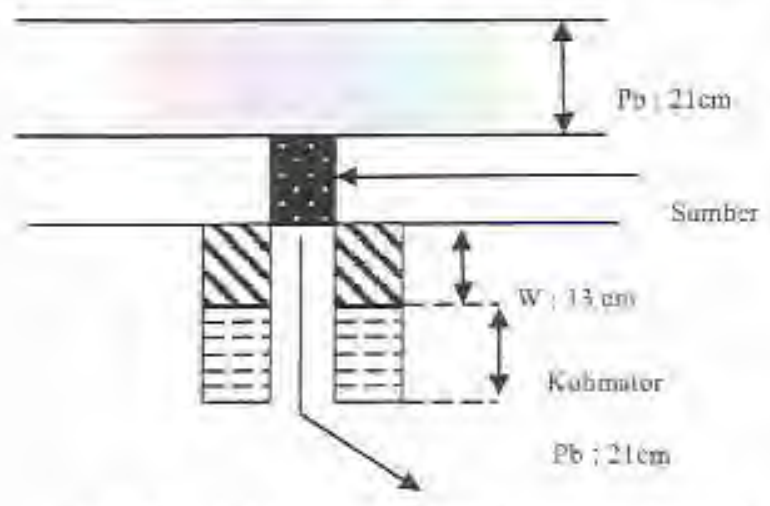

Gambar 4. Hasil rancangan susunan perisai radiasi pada kepala sumber pada posísi penyinaran.

\section{KESIMPULAN}

Perangkat radioterapi pada bagian kepala sumber yaitu tempat sumber isotop berada pada posisi penyinaran, dilengkapi dengan perisai radiasi. Berdasarkan hasil perhitungan perisai radiasi agar perangkat mampu melindungi bagian tubuh yang tidak diterapi sehingga memenuhi ketentuan keselamatan yang dipersyaratkan, maka desain tebal perisai radiasi perangkat :
- Bagian atas dan samping perisai radiasi terbuat dari bahan $\mathrm{Pb}$ dengan ketebalan 21 $\mathrm{cm}$.

- Bagian bawah, terpasang perisai radiasi W tebal $13 \mathrm{~cm}$ dengan dilengkapi kolimator dari bahan $\mathrm{Pb}$ yang berfungsi untuk menyearahkan paparan yang terdiri ? sirip dengan tebal $3 \mathrm{~cm}$ sehingga ketebalan total $21 \mathrm{~cm}$.

\section{DAFTAR PUSTAKA}

1. Santoso W.B., Disain Dasar Perangkat Radioterapi Eksternal Menggunakan Co60 , Proposal Program Insentif Peningkatan Kemampuan Penelitian dan Perekayasaan (PI-PKPP), PRPN - BATAN, (2012).

2. Anonim, Keselanatun Radiasi dalam Penggunaan Radioterapi, Keputusan Kepala Badan Pengawas Tenaga Nuklir No: 3, (2013).

3. Chamber H., Introchucsion to Health Physics, Pergamon Press, Nortwestern University, (1983).

4. Wiryosimin S., Mengenal Asas Proteksi Radiasi. ITB Bandung, (1995).

5. Anonim, Data on Shielding from Jonizing Radiation, British Standards Institution Part 1, Shielding from Gamma Radiation, London, (1966).

6. Anonim, Radiation Protection in the Design of Radioteraphy Fasilities, IAEA. Sefety Report Series No 47, Vienna, (2006).

7. Jaeger R.G., Engineering Compendium on Radiation Shielding, International Atomic Energy Agency Vienna, New York, (1968).

8. Anonim, Operation Instruction, Fcc 8000 F Co-60 Therapy Unit, Shandong Xinhua Medical Instrument Co, (1999).

9. Anonim, Rad Pro Calculation, www.radprocalcalator.com/Gamma.aspx. 